\title{
Experimental Investigation on Granite Cutting by Means of Diamond Frame Saw
}

\author{
Junjie Wu \\ Shandong University \\ Jinsheng Zhang ( $\square$ zhangjs@sdu.edu.cn ) \\ Shandong University \\ Heng Zhang \\ Shandong University \\ Peiyu Dong \\ Shandong University \\ Congsen Ouyang \\ Shandong University \\ Kaida Wang \\ Shandong University
}

\section{Research Article}

Keywords: Diamond framesaw, Granite cutting, Diamond particles, Wear morphology, Saw kerf

Posted Date: September 2nd, 2021

DOl: https://doi.org/10.21203/rs.3.rs-855683/v1

License: (c) (i) This work is licensed under a Creative Commons Attribution 4.0 International License. Read Full License

Version of Record: A version of this preprint was published at The International Journal of Advanced Manufacturing Technology on November 9th, 2021. See the published version at https://doi.org/10.1007/s00170-021-08300-y. 


\title{
Experimental investigation on granite cutting by means of diamond frame saw
}

\author{
Junjie $\mathrm{Wu}^{\text {a, b, c }}$, Jinsheng Zhang a, b, c,*, Heng Zhang a, b, c, Peiyu Dong a, b, c, Congsen Ouyang a, b, c, Kaida \\ Wang $\mathrm{a}, \mathrm{b}, \mathrm{c}$ \\ ${ }^{a}$ School of Mechanical Engineering, Shandong University, Jinan 250061, China \\ ${ }^{b}$ National Demonstration Center for Experimental Mechanical Engineering Education/Key Laboratory of \\ High Efficiency and Clean Mechanical Manufacture of MOE, Jinan 250061, China \\ ${ }^{c}$ Research Centre for Stone Engineering (Shandong Province), Jinan 250061, China
}

\begin{abstract}
A great quantity of granite sawing experiments was carried out to explore the cutting performance of frame sawing machine with the horizontal reciprocating cutting mode. A model of average thickness of cutting chip was established, and characteristics of cutting forces were analyzed. The mechanism of wear was revealed by analyzing the width of the saw kerf and the wear morphology of the diamond segments. The results showed that the wear resistance and the cutting forces increase as the feed speed. The cutting forces change abruptly at the reversing point during granite cutting. At the same time, the proportion of macro-fractured and pulled-out particles and the mean wear rate of segments increase with the feed speed, and the mean protrusion height of the grits is less than $100 \mu \mathrm{m}$. The width of the saw kerf is gradually reduced as the sawing progresses, forming an inverted cone with a large upper side and a small lower side. Besides, the studies found that the wear of the segments remains consistent in two directions. The prominent phenomenon of the diamond particles on the side surface is more obvious as the feed speed increases. The research can provide certain data support for granite cutting, and lay the foundation for the subsequent optimization of the structure and equipment.
\end{abstract}

Keywords: Diamond frame saw; Granite cutting; Diamond particles; Wear morphology; Saw kerf

\footnotetext{
* Corresponding author at: School of Mechanical Engineering, Shandong University, Jinan, 250061, China. E-mail address: zhangjs@sdu.edu.cn (J. Zhang).
} 


\section{Introduction}

With the vigorous development of architectural decoration, precision machinery and other industries, natural stones are widely used due to their beautiful appearance, stable physical, and chemical properties. The sawing equipment of diamond circular saw, frame saw and wire saw are introduced to machining these natural stones, which has caught widespread attention. Granite is the high hardness and brittleness material, how to achieve efficient sawing has become an important direction in hard stone processing.

The efficient processing of the equipment is influenced by many factors: cutting tools, hardness of stone and so on. Traditionally, most scholars use the cutting forces and tool wear as evaluation indicators of sawing performance. Many scholars have conducted research and analysis on the cutting forces in order to study the sawing mechanism. Turchetta et al. [1-3] built the cutting force model of a diamond particle and measured the cutting forces under kinds of processing conditions. The function of the cutting forces and the average thickness of sawing chip was obtained by regression analysis. Besides, a theoretical processing model for natural stone was obtained based on the cutting forces. His researches provided the theoretical basis for process optimization and selection of processing parameters. Xu et al. [4] established the undeformed chip to characterize the granite sawing process. The result showed that the normal force of each particle increases with the maximum thickness of chip. The model of the cutting forces was established and the chips were quantified by Polini et al. [5] through the behavior of sawing forces. The result indicated that the depth of cut has the prominent effect on the sawing forces. The predictive model of sawing power was proposed by Huang et al. [6], which experimentally validated and modified based on the tangential force in the diamond circular saw. It provided the basis for optimizing sawing parameters and reducing energy consumption. Bayram and Tumac et al. [7,8] deduced the experimental formula for predicting the cutting performance of sawing tools, which indicated that the cutting forces are relation to the stone types closely. Schulze et al. [9] established a multiple regression model that was used in kinematics simulation to provide the guidance for calculating the machining force and direction for milling operation. Gelfusa [10] et al. used a single diamond-coated bead to cut granite and established a model of the cutting force components. The results showed that cutting forces increase as the feed speed. Wang et al. [11] found that the forces of cutting depend on the sawing position, sawing direction, sawing path, cutting depth of per grit and coolant. Simultaneously, Wang et al. [12] used a computer to simulate the sawing forces of sawblade, segments and diamond particles during sawing showed that the feed speed and cutting performance determine the sawing force and segment wear.

To optimize the processing performance of the sawing tools, the wear of diamond segments was studied by many scholars. A set of methods for measuring the macroscopic geometric wear of diamond tools were established to characterize the wear of sintered diamond tools by Polini et al. [13-15]. In addition, the sensors are used to collect forces and acceleration signals in three directions under different processing conditions and perform the signal processing analysis. The results showed that the force or acceleration signal feature can provide an effective mean of real-time monitoring of the tool wear. Di Ilio and Ersoy et al. [16,17] proposed a theoretical model of tool wear. The results indicated that the diamond particles must maintain a proper shedding rate to keep selfsharpening, and the matrix must be worn at a proper rate as well. Wear characteristics of diamond with a circular saw during the granite sawing and a load model of combination saw were studied by Zhou et al. [18]. The results showed that uneven load is the main factor for the inconsistent wear of combined segments. The equivalent chip thickness models were established by Konstanty et al. to balance the relationship between sawing efficiency and tool life $[19,20]$. The influence of martensite transformation on the wear behavior of iron-based diamonds was explored. The analysis result showed that the diamond concentration is the main factor affecting the wear rate. A new model of the unit wear of diamond segments was proposed to evaluate the sawing performance by Bayram et al. [21]. The determination coefficient of the regression equation is determined based on experimental data that tested on the diamond frame saw. The result showed that the wear of diamond segments was proportional to the feed speed.

Most of the literature focuses on the diamond circular saw and the diamond wire saw, few references related to diamond frame saws. However, attentions are also worthwhile to be attracted by diamond frame saws because of the advantages of high processing efficiency, great processing quality, low noise, and dust pollution [22], which makes them especially suitable in the sawing of large-size slabs. The sawing of stone blocks realized in the reciprocating motion of diamond segments by diamond frame saw, diamond segments are welded on sawblades and sawblades are tensioned on the saw frame. Harsh environment is generated as well as that diamond segments are severely worn during the process of reciprocating motion. The saw efficiency and accuracy decrease dramatically due to worn diamond segments. Therefore, scholars have conducted a series of researches on diamond segments. The mathematical equation of the optimal system parameters is established by Li et al. [23] based on the studies of the sawing motion mechanism, which provided the basis for the trajectory design. Wear of diamond segments and cutting forces were obtained by Wang et al. ${ }^{[24]}$ through the sawing experiments. The results indicated that the feed speed and sawing performance determine the forces of sawing and wear of segments. Sun et al. [25] established a model between rock characteristics and wear through experiments. Wang et al. [26] 
analyzed the segments wear with different composition of matrix under two sawing modes. The results showed that the wear rate of the iron-based segments is higher than that of the cobalt-based segments. To reduce segment wear and optimize the sawing performance of equipment, comparing with wire saws and circular saws that the matrix tail [27-31] formed behind diamond particles. Zhang et al. [22,32,33] designed a frame sawing machine with an eccentric hinge guide mechanism which diamond particles under the new type of sawing are easy to form the matrix tail which improves the holding force and reduces the falling from the diamond particles. Webb et al. [34] observed the wear of segments and sawing forces in the process of sawing stone, and indicated that higher sidewall wear may cause the blade to 'knife-edging' and accelerated radial wear. The sawing experiment on the frame saw with a reciprocating swing mode was conducted by Dong et al. [35]. The results demonstrated that decreasing of the value of cutting arc and segments participating in cutting could improve stability of sawblades. Li et al. [36] found that the roughness of workpiece decreases as the wire speed increases when the speed is low.

The topic of this paper aims at the sawing performance of frame saw with the horizontal reciprocating cutting mode. The average thickness of cutting chip model was established and the reasons for the difference in cutting forces on segments was explained. The mechanism of the segment wear and the discrepancy of saw kerfs is investigated based on wear characteristic of the diamond segments and the width of the saw kerf.

\section{Experiment procedure}

\subsection{Sawing equipment}

Experiments were conducted on the diamond frame saw with horizontal reciprocating sawing mode, as shown in Fig. 1. Sawblades are installed on frame of the diamond frame saw and diamond segments are welded at the bottom of sawblade body.

The equipment is mainly used to saw large-size natural stone into slabs of specified thickness. The sawing movement mainly includes horizontal reciprocating movement and feed movement of stone. The horizontal reciprocating movement is realized by the crank connecting rod mechanism and the feed movement is driven by the lifting device. The parameters of sawing are listed in Table 1.
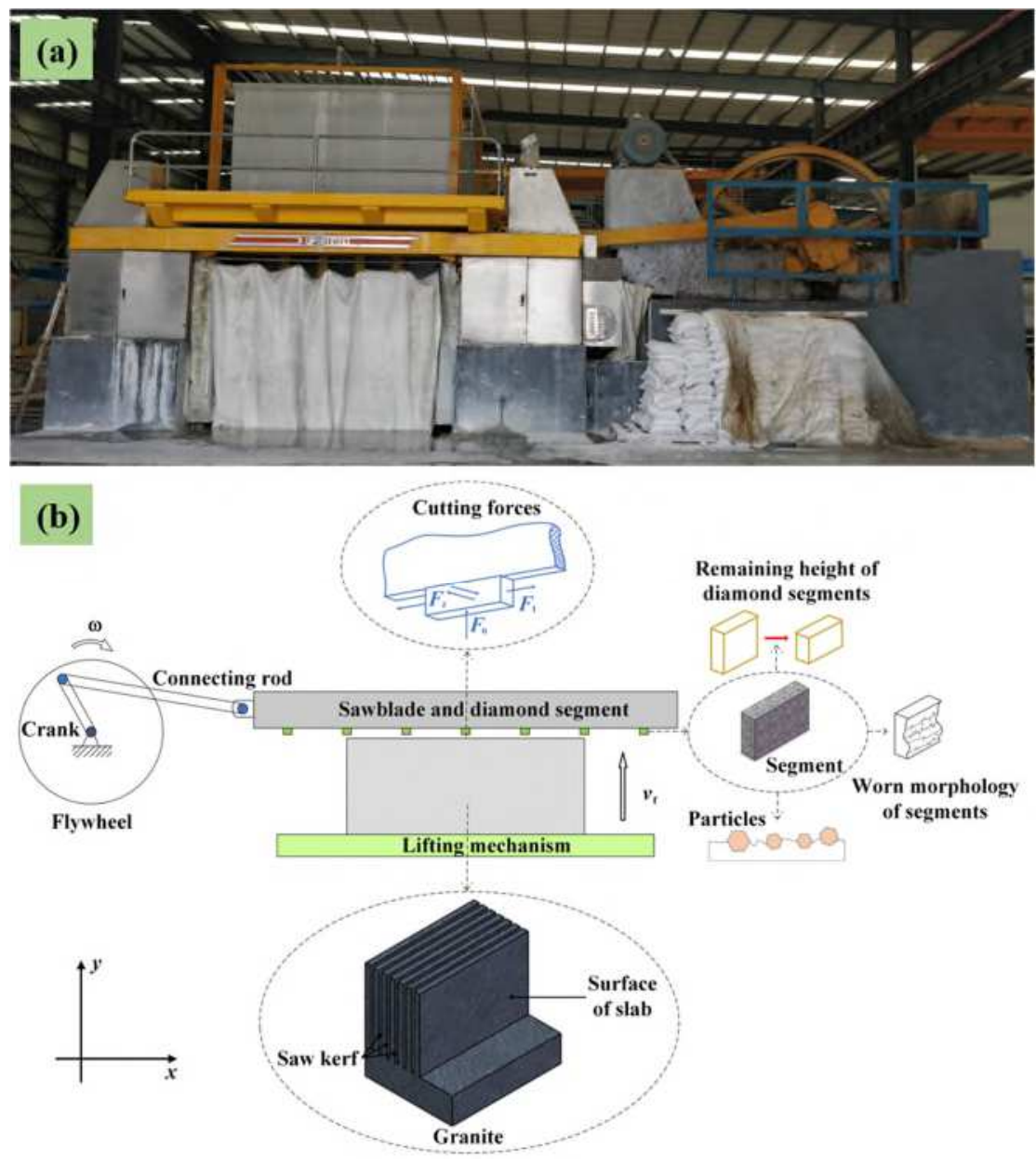
Fig. 1. Granite sawing by the diamond frame saw: (a) General view of the diamond frame saw; (b) The sawing system of experiment device.

Table 1

Sawing parameters of equipment.

\begin{tabular}{cc}
\hline Parameters & Values \\
\hline Dominate motor $(\mathrm{kw})$ & 110 \\
Flywheel speed (r/min) & 60 \\
Feed motor $(\mathrm{kw})$ & 15 \\
Stroke $(\mathrm{mm})$ & 600 \\
The flow rate of cooling water $(\mathrm{L} / \mathrm{min})$ & 10 \\
\hline
\end{tabular}

\subsection{Sawing tools and workpiece}

The experimental tools were sawblades with dimensions of $4100 \mathrm{~mm}$ (length) $\times 3.5 \mathrm{~mm}$ (width) $\times 180 \mathrm{~mm}$ (height) and diamond segments. Table 2 provided some information of the diamond segment. Two pieces of Brazilian gold granite with different sizes were used as experimental workpieces, in which the sizes of $200 \mathrm{~mm}$ (length) $\times 80 \mathrm{~mm}$ (width) $\times 80 \mathrm{~mm}$ (height) were taken to measure the sawing force, the sizes of $2600 \mathrm{~mm}$ (length) $\times 1500 \mathrm{~mm}$ (width) $\times 1950 \mathrm{~mm}$ (height) was adopted to analyze the characteristics of segment wear. The main characteristic parameters of granite are displayed in Table 3.

Table 2

Information of diamond segments.

\begin{tabular}{cc}
\hline Diamond segments & Parameters \\
\hline Matrix composition & Iron 39.76\%, Copper 27.67\%, Cobalt 17.60\% \\
& Silicon $9.32 \%$, Aluminum $2.04 \%$, Calcium 1.92\%, \\
Size (length $\times$ width $\times$ height $)$ & Carbon $1.69 \%$ \\
Particle size $($ mesh) & $23 \times 4.8 \times 14 \mathrm{~mm}^{3}$ \\
Concentration & $40 / 50$ \\
\hline
\end{tabular}

Table 3

Characteristic parameters of granite.

\begin{tabular}{cc}
\hline Granite & Parameters \\
\hline Volume ratio of major ore components & Quartz 25\%, K-feldspar 40\%, Plagioclase 33\%, Biotite \\
Shore hardness & $1 \%$, Others 1\% \\
Bending strength (MPa) & 97 \\
Compressive strength (MPa) & 14.5 \\
\hline
\end{tabular}

\subsection{Sawing tests}

The cutting forces $\left(F_{\mathrm{n}}, F_{\mathrm{t}}\right.$ and $\left.F_{\mathrm{z}}\right)$ in three directions were measured by a Kislter dynamometer (Kislter 9257B). The schematic illustration of cutting forces experiment is displayed in Fig. 2. The height of segments and the width of saw kerfs under different cutting parameters were obtained by a vernier caliper. Each measurement was repeated four times and mean values were calculated. Then the detail information of segments was observed by three-dimensional imaging system (VHX-600) and scanning electron microscopy (JSM-6610LV). Besides, the protrusion height of diamond grits was measured through a laser scanning confocal microscope (LSM800), as displayed in Fig. 3. 


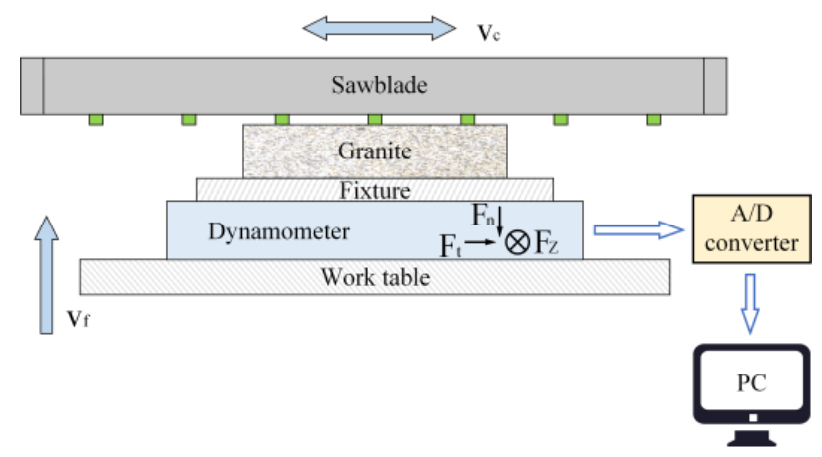

Fig. 2. The schematic of sawing experiment.

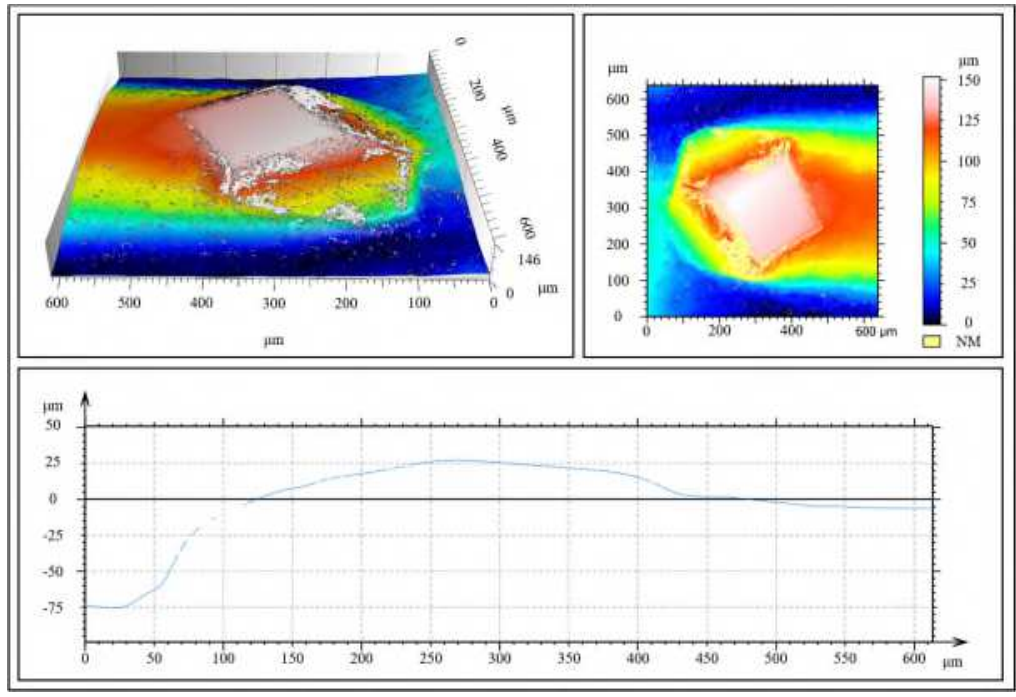

Fig. 3. Measurement of the protrusion height.

\section{Results and discussions}

\subsection{Cutting forces}

\subsubsection{Characteristics of cutting forces}

The forces are measured to verify its effect on the sawing process. Fig. 4 shows the cutting forces in the stone processing. The forces change periodically; besides, the feed cutting force $\left(F_{\mathrm{n}}\right)$ and the cutting force $\left(F_{\mathrm{t}}\right)$ show a tendency of decreasing firstly and then increasing in a single stroke, the minimum value and maximum value are obtained at the midpoint and the reversing point, respectively. More specifically, the cutting force has positive and negative changes in the forward and return strokes.
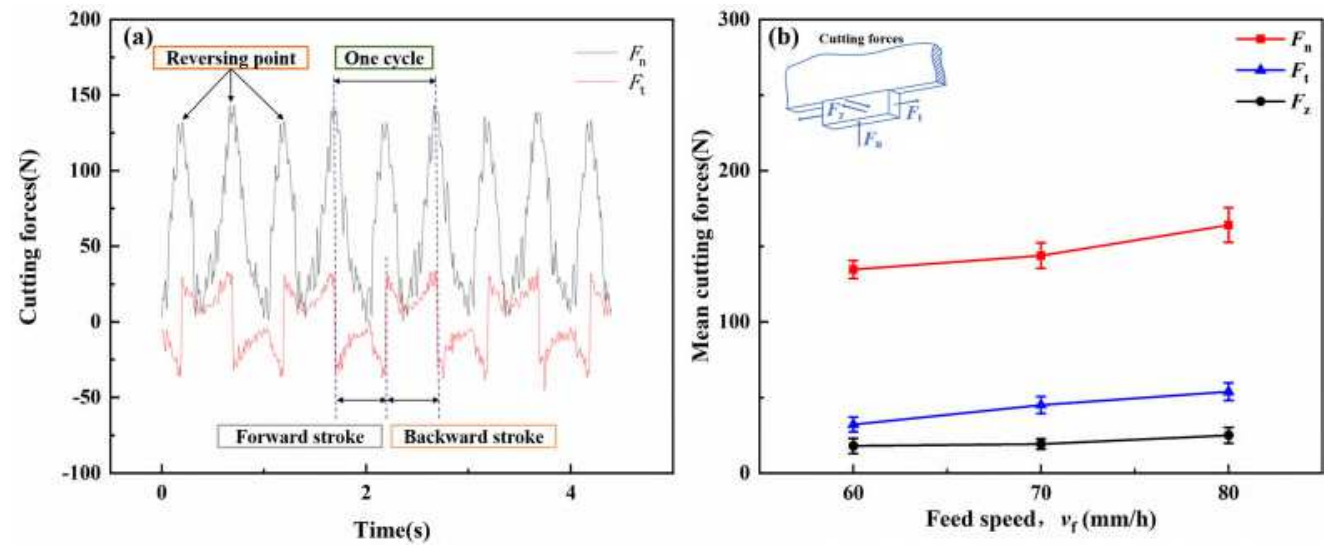

Fig. 4. (a) The force signals; (b) The cutting forces at different feed speeds. 
This is because the horizontal motion and vertical feed motion of sawing machine are independent. The horizontal motion is controlled by the crank linkage mechanism, and the vertical direction is fed continuously by the feed motor. When the horizontal motion reaches two reversing points, the horizontal speed is zero, but the vertical direction is still feeding at constant speed. Therefore, the cutting force reaches the maximum value at the reversing point, which is greater than the cutting force in stable cutting. Besides, the cutting forces change with the number of diamond segments which are contacting with the stone at the same time. The more the number of diamond segments, the greater the cutting forces. The cutting forces of a segment at different feed speed are displayed in Fig. 4(b). $F_{\mathrm{n}}, F_{\mathrm{t}}$ and $F_{\mathrm{z}}$ are feed cutting force, cutting force and lateral force respectively. It can be observed that the feed cutting forces increases with the feed speed, which is consistent with the research results of many scholars [3-5]. As shown by experiments results, realistic machining situation could be reflected by a single diamond segment. According to Fig. 4, the feed cutting forces $\left(F_{\mathrm{n}}\right.$ and $\left.F_{\mathrm{t}}\right)$ reach $164.124 \mathrm{~N}$ and $53.86 \mathrm{~N}$ respectively when the feed speed reaches $80 \mathrm{~mm} / \mathrm{h}$, it indicates that the sawing resistance is the largest.

\subsubsection{The establishment of the average chip thickness model}

To reveal the relationship between the sawing parameters and the cutting forces, the theoretical model of average chip thickness changing with cutting parameters was established, as shown in Fig. 5.

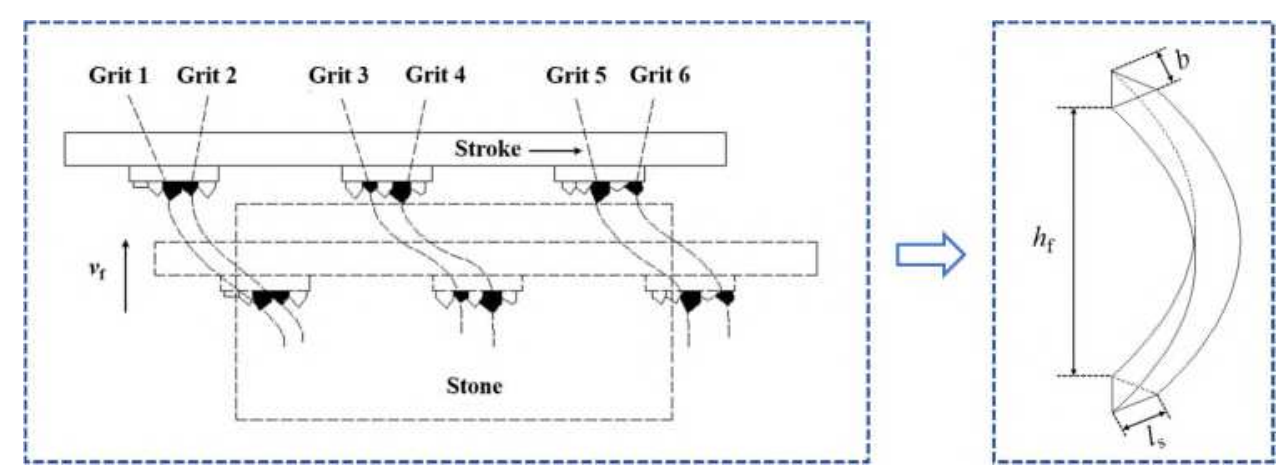

Fig. 5. The cutting chip in a single stroke time.

The cutting chip can be regarded as a pentahedron with a triangular cross section within a single stroke time (Assuming that each diamond particle is cutting from beginning to end). The feed rate ( $\mathrm{mm}$ ) of a segment in a single stroke can be expressed as:

$h_{f}=\frac{v_{f}}{120 \times n}$

where $v_{f}(\mathrm{~mm} / \mathrm{h})$ is the feed speed of the stone; $n(\mathrm{rpm})$ is the rotating speed of the flywheel.

Therefore, the largest undeformed volume of cutting chip $\left(\mathrm{mm}^{3}\right)$ removed in a single stroke time can be represented as:

$V=\frac{h_{f} \times l_{s} \times b}{2}$

where $l_{s}(\mathrm{~mm})$ is the center distance between two diamonds, $b(\mathrm{~mm})$ is the height of the cutting chip based on the bottom surface.

The diamond segment is made by sintering process, in which particles are distributed on the segment randomly, so the average depth of cut ( $\mathrm{mm})$ can be expressed by Eq. (3).

$h_{d}=\frac{V}{b \times L}=\frac{v_{f} \times l_{s}}{240 \times n \times L}$

where $L(\mathrm{~mm})$ is the length of stroke. The average depth of cut refers to the vertical downward displacement of diamond segments in a single stroke time, and the average thickness of cutting chip is the vertical distance between adjacent tracks in a single sawing.

Fig. 6 displays the sawing motion of sawblade in the direction of $x$ and $y$, it can be expressed by Eq. (4) and Eq. (5), respectively. 


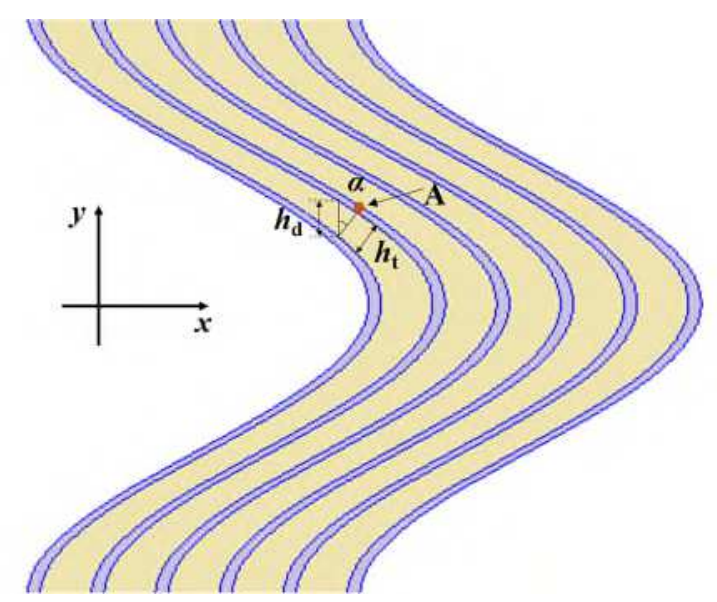

Fig. 6. The sawing motion in a single stroke time.

$x=\frac{L}{2}(1-\cos 2 \pi n t)$

$y=\frac{v_{f}}{3600} t$

The functional relationship between $y$ and $x$ be calculated by Eq. (6).

$y=\frac{v_{f}}{7200 \pi n} \arccos \left(1-\frac{2 x}{L}\right)$

Point $\mathrm{A}$ is any point except the reversing point, the slope at point $\mathrm{A}$ can be expressed as:

$$
y^{\prime}=\frac{v_{f}}{7200 \pi n \sqrt{x L-x^{2}}}
$$

The angle at point A can be described as:

$$
\tan \alpha=y^{\prime}
$$

$\cos \alpha=\sqrt{\frac{x L-x^{2}}{x L-x^{2}+A^{2}}}$

Owing to the value is 1 in the process of sawing except for the reversing point, so $\alpha$ can be ignored.

The average chipping thickness can be described as:

$h_{t}=\frac{h_{d}}{\cos \alpha}$

Therefore, the average thickness of cutting chip can be written as:

$h_{t}=\frac{v_{f} \times l_{s}}{240 \times n \times L}$

The average chipping thickness increases with the feed speed, and increases as the rotating speed decreases. According to previous studies [1,3-6] that the cutting forces increase with the average chipping thickness. Therefore, the cutting forces are increasing as the feed speed becomes higher, which leads to the wear of diamond segments.

\subsection{Wear morphology of the diamond segments}

\subsubsection{The proportion of different particles}

The wear morphology of the segments was displayed in Fig. 7. The diamond particles could be divided into six states, fresh, whole, micro-fractured, macro-fractured, blunt, and pulled-out diamond particles. Fig. 7(a) is the image of fresh diamond particles exposed after matrix consumption. Fig. 7(b) is the image of diamond particles with integrity surface and sharp cutting edge, which performs best in the cutting work. Fig. 7(c) is the image of diamond particles with slight cracks or breakage on the surface. Fig. 7(d) shows that the diamond with serious surface damage and large-scale shedding, which lost the ability of cutting. Fig. 7(e) shows that the diamond particles in an unsteady cutting state and the sharp diamond particles are blunt. Fig. 7(f) is the deep pit left after the diamond particles fell off. As illustrated in Fig. 7(f), the cracks and fractures were not found around the pits 
created by the fallen diamond particles, which indicates that diamond particle shedding is caused by insufficient holding force.
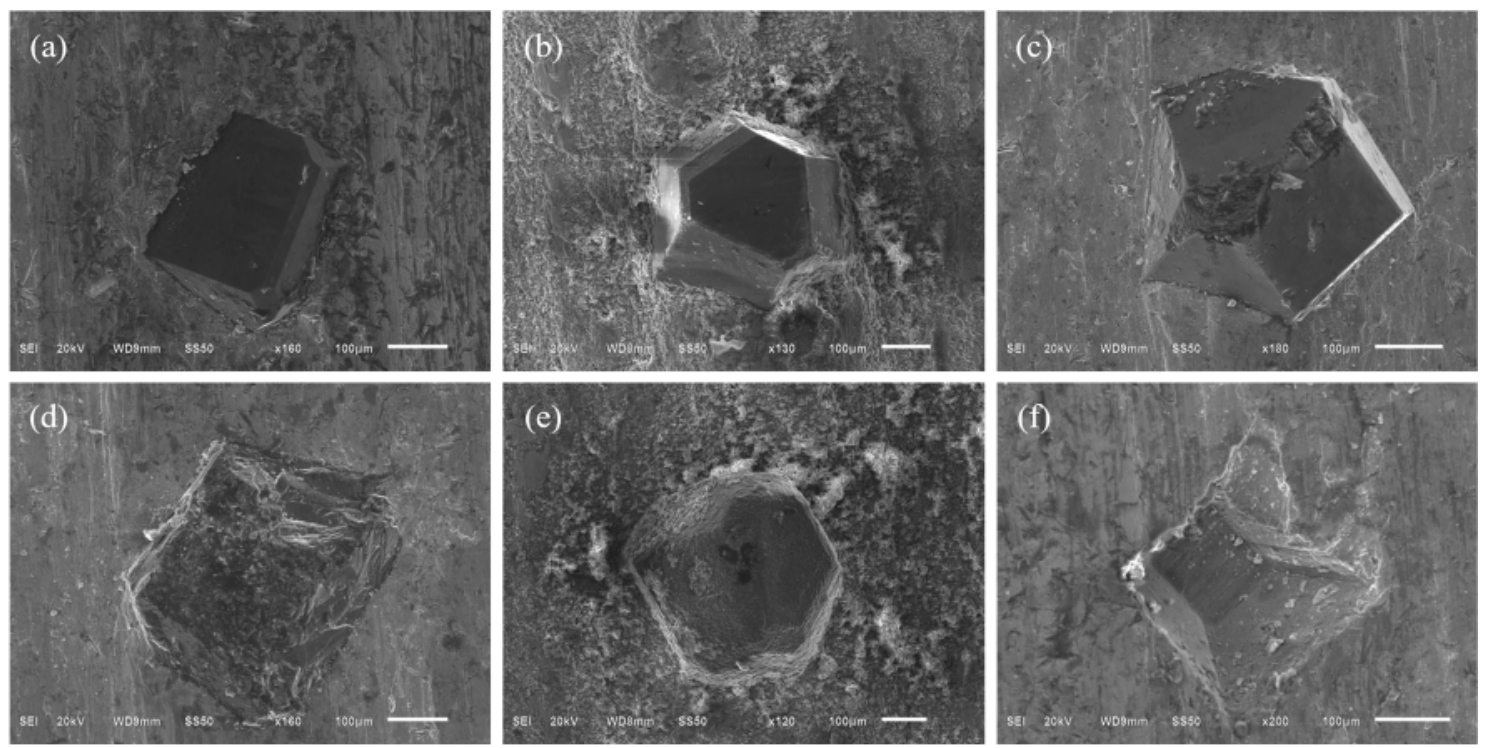

Fig. 7. Different categories of diamond particles observed with SEM: (a) Fresh; (b) Whole; (c) Micro-fractured; (d) Macro-fractured; (e) Blunt; (f) Pulled-out.

When the rotating speed of the flywheel is maintained at $60 \mathrm{r} / \mathrm{min}$, the proportion of macro-fractured and pulledout particles on segments at different feed speeds is presented in Fig. 8. The results reveal that the values were more than $1 / 3$, which increased from $29.6 \%$ at $60 \mathrm{~mm} / \mathrm{h}$ to $40 \%$ at $80 \mathrm{~mm} / \mathrm{h}$. This is because the cutting forces are directly related to the state of diamond particles. The higher the feed speed, the larger the average thickness of cutting chip, the greater the cutting force as analyzed in Section 3.1. Therefore, the phenomenon of macrofractured and pulled-out particles could be more obvious.

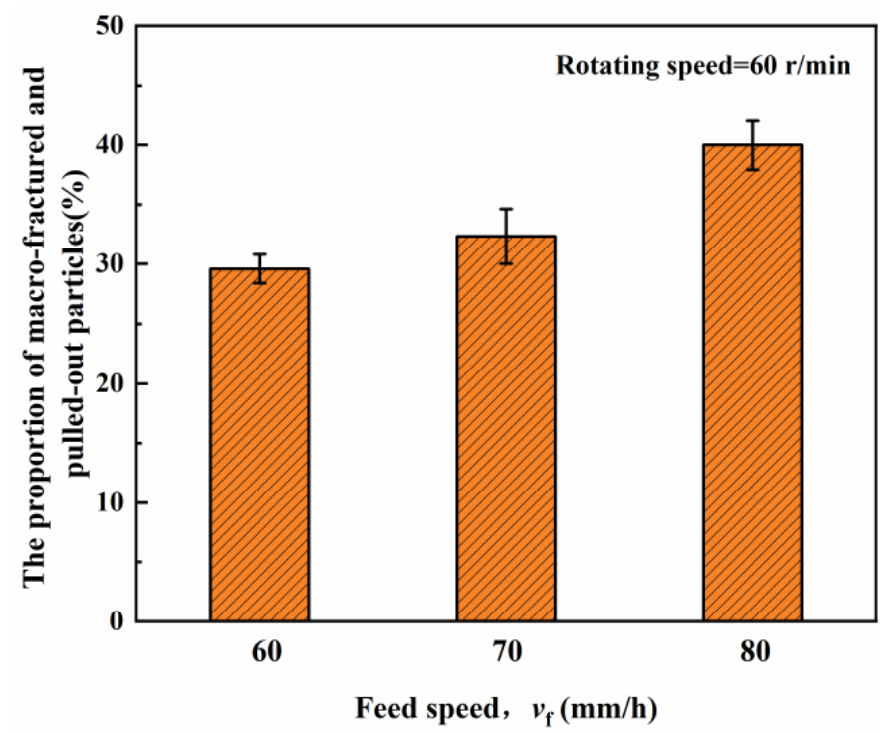

Fig. 8. The proportion of macro-fractured and pulled-out particles at different feed speeds.

The protrusion height of diamond particle obtained through laser scanning confocal microscope. 30 diamond particles are measured, and each measurement was repeated three times. Finally, the average protrusion height of $86.3 \mu \mathrm{m}$ is got after calculating. The results show that the protrusion height of diamond particles is below $100 \mu \mathrm{m}$. The cutting forces become larger during sawing hard stone such as granite, which causes the diamond particles to fall off before performing their cutting function. At the same time, the diamond particles are prone to breakage, resulting in the overwhelming of macro-fractured particles when the mechanical impact load is large, as shown in Fig. 9. The forces on diamond particles become larger and the diamond particles fall off and broken macroscopically become more serious as the feed speed increases, so the mean protrusion height of the diamond segments decreases. Ultimately, the diamond segments lose its sawing ability. This is consistent with the analysis 
in section 3.1, the cutting forces become larger and the proportion of macro-fractured and pulled-out grits become higher as feed speed gets higher.

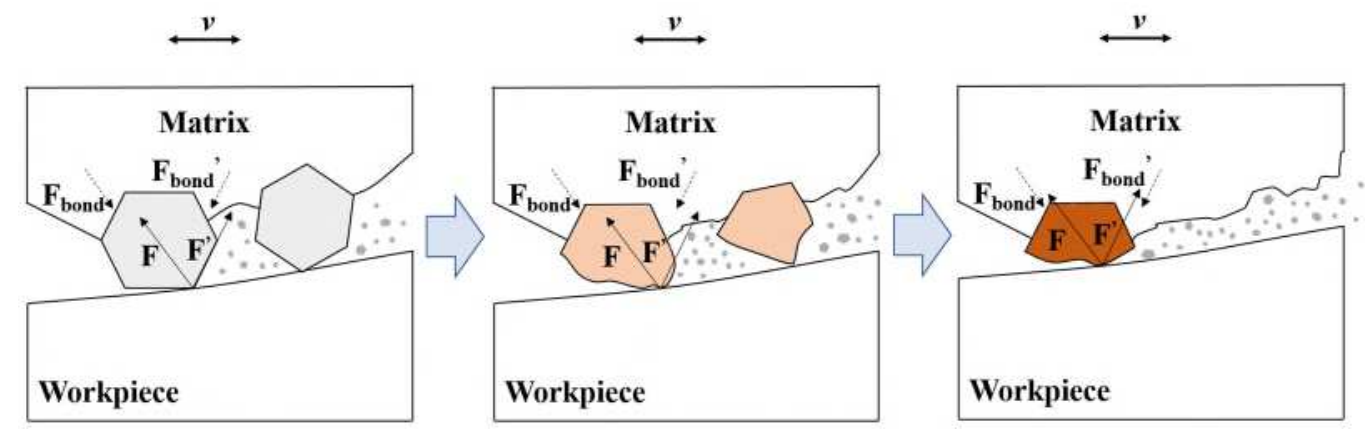

Fig. 9. The principle of macro-fractured diamond particles.

\subsubsection{The mean wear rate of segments}

The mean wear rate can be calculated by the initial height and remaining height of segments, as displayed in Fig. 10. The wear rate of segments increases with the feed speed obviously. Compared with wear rate of segments at $60 \mathrm{~mm} / \mathrm{h}$, the value at $80 \mathrm{~mm} / \mathrm{h}$ increases significantly, reaching $919.19 \mu \mathrm{m} / \mathrm{m}^{2}$. The increase of the feed speed causes the depth of cut of diamond particles to increase, thereby increasing the cutting force, resulting in an increasing in the number of particles which are macro-fractured and falling off, and a decreasing in the height of diamond particles.
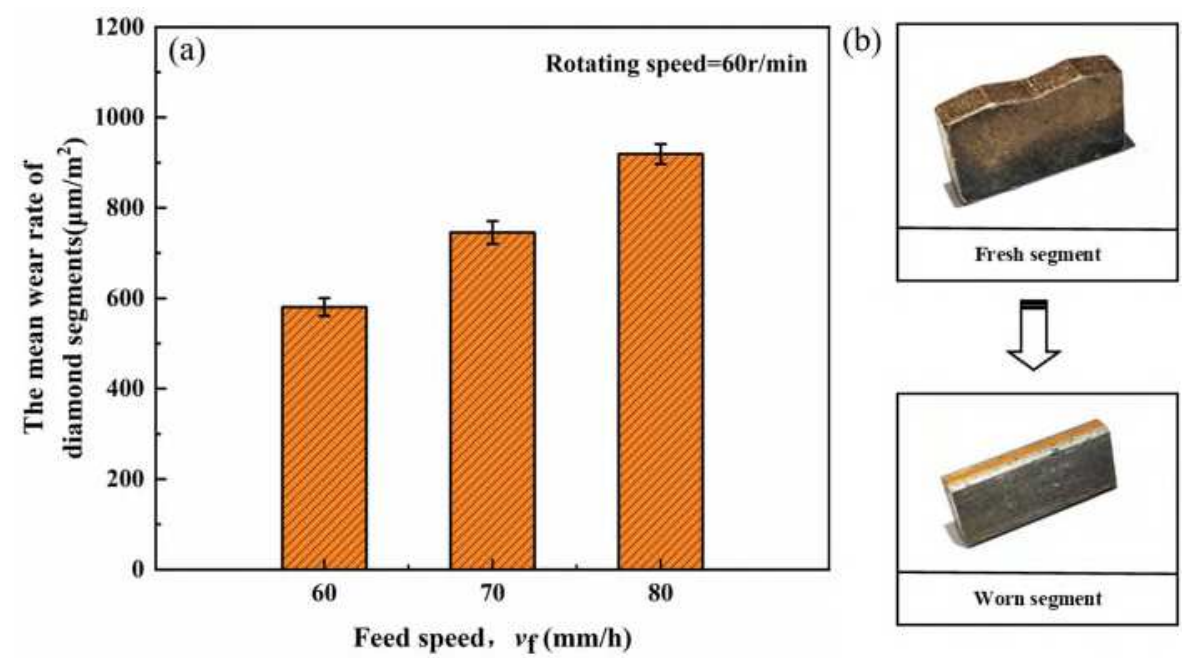

Fig. 10. The wear of diamond segments: (a) The mean wear rate of diamond segments. (b) Fresh segment and worn segment.

The result of this phenomenon is that the contact area between the segments and the stone is further increased, thereby reducing the holding force of particle, and consuming the metal matrix of the segments. Consequently, the diamond segment wear further aggravates and forms a vicious circle.

\subsection{The width of saw kerf}

The width of saw kerfs at different feed speed in the experiment is also measured to explore the sawing performance of the sawblade in granite cutting, as shown in Fig. 11. It can be found that the width of the saw kerf is gradually reducing as the sawing progresses, forming an inverted cone with a large upper side and a small lower side. Besides, the gap of the saw kerf increases with the feed speed in the sawing process. 


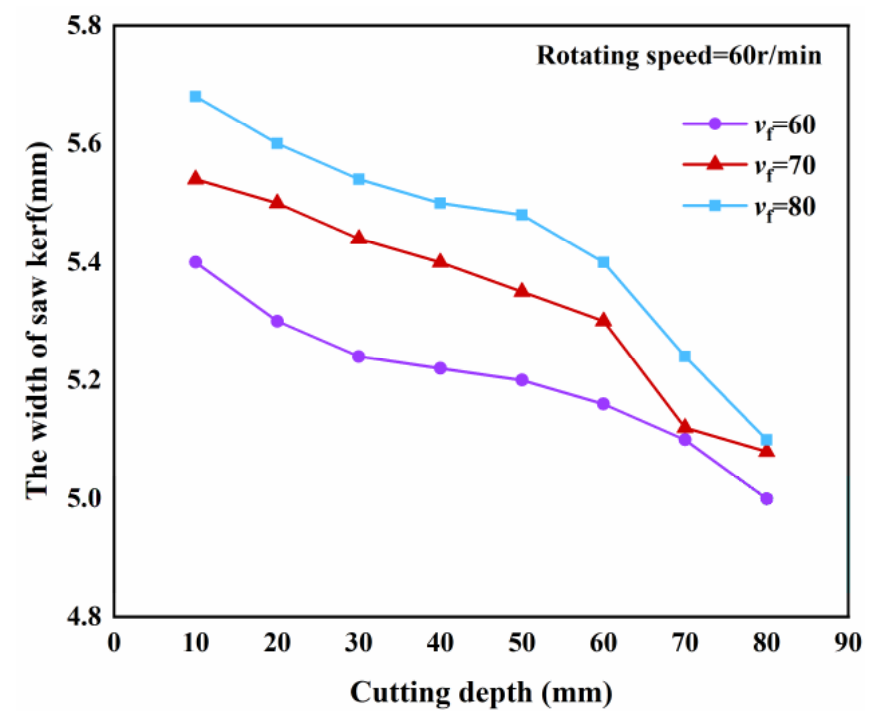

Fig. 11. The width of saw kerf at different feed speeds.

Based on the existing studies [37-39], the appearance of the inverted cone sawing kerf can be affected by the two factors. The first factor is the excessive force on the saw blade causes the swing in the saw kerf, which makes the sawing process unstable, resulting in a difference in sawing width. Moreover, it can be seen from the broken phenomenon on the top of the stone that the saw blade has deviated, as illustrated in Fig. 12. The second factor is the segment gradually become narrower due to the wear on the side, which makes the width of the saw kerf smaller. When the cutting forces of the saw blade exceed the critical instability forces, the saw blade is prone to instability and deviates from the original trajectory. The diamond frame saw with horizontal reciprocating sawing method is not suitable for cutting granite because of the instability of the sawblade and severe wear of the segment.

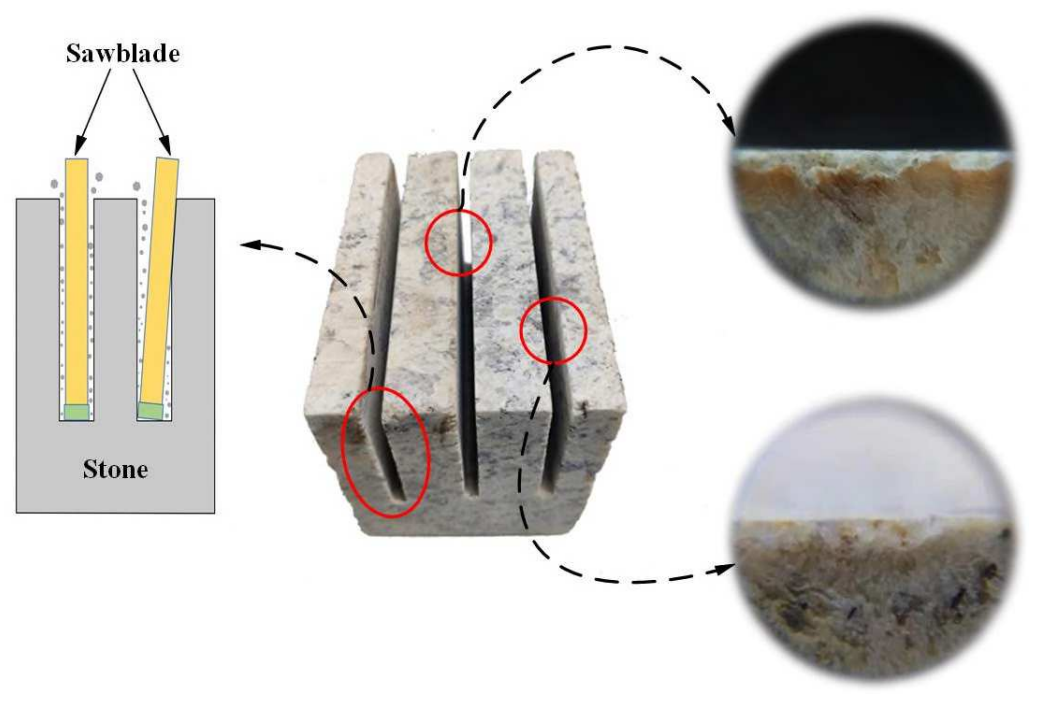

Fig. 12. Edge chipping of the stone.

\subsection{Side wear characteristic of the diamond segments}

The side wear characteristic of the diamond segments at different feed speeds is shown in Fig. 13 and Fig. 14. Each picture is stitched together from 4-8 pictures. It displays that the higher the feed speed, the more diamond grits on segment surface, and the more obvious protruding phenomenon of particles on the surface. The phenomenon is attributed to the instability of the sawblade results in varying degrees of sharpness on the side of the segment. The cutting forces become larger as the feed speed becomes higher, therefore, the sawblades are more likely to lose stability, the forces on the side of diamond segment increase, resulting in more diamond particles appearing on the segment. This is consistent with the analysis of the bottom surface of the diamond segments studied in section 3.2. The wear on the bottom and side surfaces of the diamond segments is more obvious as the feed speed increases. 

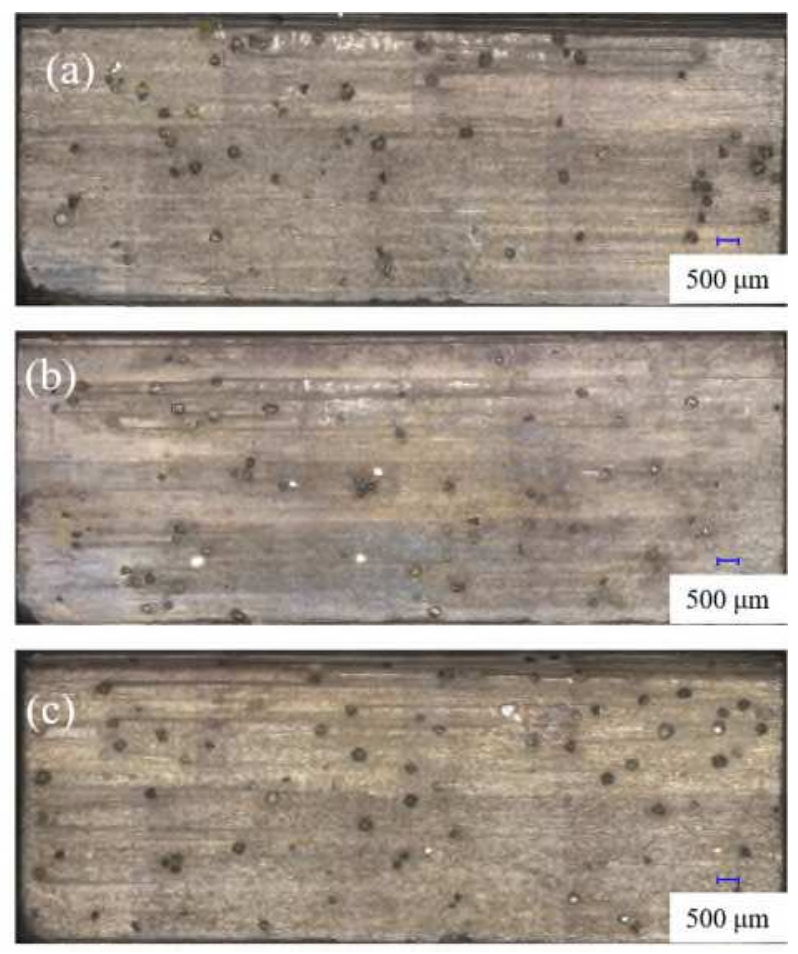

Fig. 13. The side wear characteristic of the diamond segments with the remaining height of $9 \mathrm{~mm}$ : (a) $v_{\mathrm{f}}=60$ $\mathrm{mm} / \mathrm{h}$; (b) $v_{\mathrm{f}}=70 \mathrm{~mm} / \mathrm{h}$; (c) $v_{\mathrm{f}}=80 \mathrm{~mm} / \mathrm{h}$.
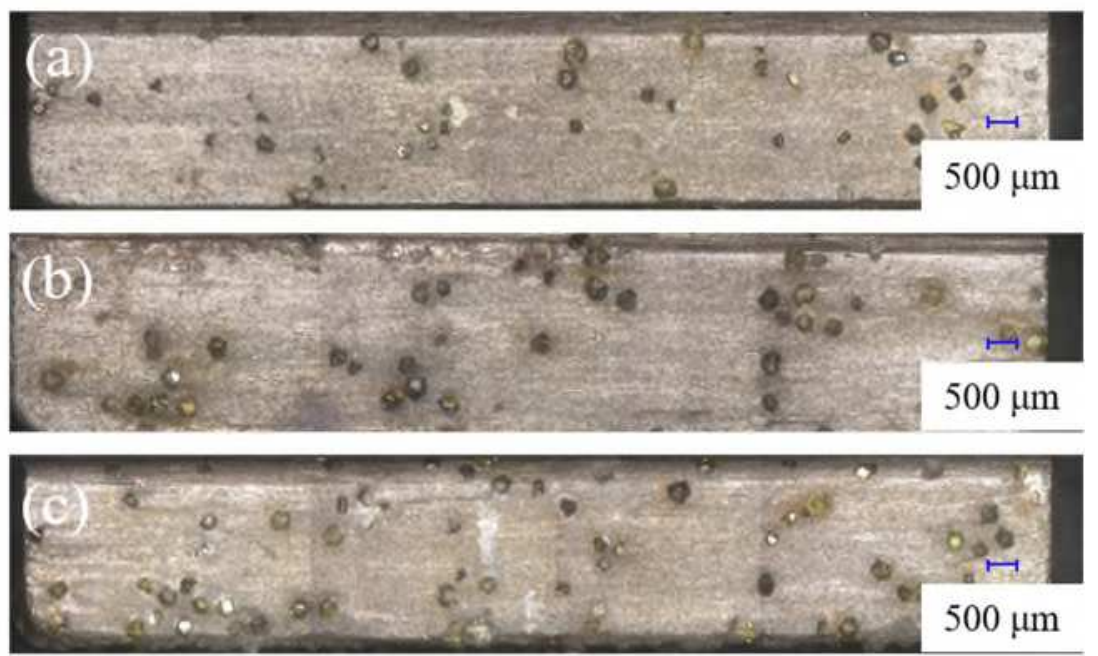

Fig. 14. The side wear characteristic of the diamond segments with the remaining height of $4 \mathrm{~mm}$ : (a) $v_{\mathrm{f}}=60$ $\mathrm{mm} / \mathrm{h}$; (b) $v_{\mathrm{f}}=70 \mathrm{~mm} / \mathrm{h}$; (c) $v_{\mathrm{f}}=80 \mathrm{~mm} / \mathrm{h}$.

\section{Conclusions}

The cutting forces, wear of the segments and the width of saw kerf were experimented on the diamond frame saw with horizontal reciprocating cutting mode to explore sawing performance during granite machining. The conclusions are as follows:

(1) The average cutting thickness, sawing resistance, and cutting forces increase with the feed speed, and there are abrupt changes in cutting forces at the reversing point.

(2) The proportion of macro-fractured and pulled-out particles are more than $1 / 3$, which increased from $29.6 \%$ at $60 \mathrm{~mm} / \mathrm{h}$ to $40 \%$ at $80 \mathrm{~mm} / \mathrm{h}$. The mean wear rate of the segments increases with the feed speed, and the mean height of the diamond particles is low due to the large load during the process of sawing granite. 
(3) The width of the saw kerf is gradually reduced as the sawing progresses, forming an inverted cone with a large upper side and a small lower side. Besides, the gap of the saw kerf increases with the feed speed during sawing.

(4) The diamond segments wear in two directions $(y, z)$ increases as the feed speed becomes higher, and the prominent phenomenon of grits on the side surface is more obvious.

\section{Funding}

This work was funded by Provincial Key R\&D Program of Shandong Province, China [NO.2019GGX104022], Scientific and Technological Innovation Project of Rizhao [NO.2019CXZX1109] and Scientific and Technological Innovation Project of Rizhao [NO.2020CXZX1201]. The authors thanks Rizhao Hein Saw Co., Ltd. for supplying the diamond frame saw and experimental sites.

\section{Conflicts of interest}

We declare that we do not have any commercial or associative interest that represents a conflict of interest in connection with the work submitted.

\section{Availability of data and material}

The data and material during the study are listed in this paper.

\section{Code availability}

Not applicable.

\section{Ethics approval}

Not applicable.

\section{Consent to participate}

Yes.

\section{Consent for publication}

Yes.

\section{Authors' contributions}

Junjie Wu: Investigation and writing.

Jinsheng Zhang: Review and editing.

Heng Zhang: Advice and guidance.

Peiyu Dong: Model improvement.

Congsen Ouyang: Picture processing.

Kaida Wang: Review.

\section{References}

[1] S. Turchetta, Cutting force on a diamond grit in stone machining, Int J Adv Manuf Technol. 44 (2009) 854861.

[2] S. Turchetta, W. Polini, Cutting force in stone lapping, Int J Adv Manuf Technol. 57 (2011) 533-539.

[3] Turchetta S. Cutting force and diamond tool wear in stone machining, Int J Adv Manuf Technol. 61 (2012) 441-448.

[4] X. Xu, Y. Li, M.Stephen, Forces and Energy in Circular Sawing and Grinding of Granite, J Manuf Sci E. 123 (2001) 13-22.

[5] W. Polini, S. Turchetta, Force and specific energy in stone cutting by diamond mill, Int J Mach Tool Manu. 44 (2004) 1189-1196. 
[6] G. Huang, M. Zhang, H. Huang, Estimation of Power Consumption in the Circular Sawing of Stone Based on Tangential Force Distribution, Rock Mech Rock Eng. 51 (2018) 1249-1261.

[7] F.Bayram, Prediction of sawing performance based on index properties of rocks, Arab J Geosci. 6 (2013) 4357-4362.

[8] D. Tumac, H. Copur, C. Balci, Investigation into the Effects of Textural Properties on Cuttability Performance of a Chisel Tool, Rock Mech Rock Eng. 51 (2018) 1227-1248.

[9] V. Schulze, C. Becke, R. Pabst, Specific machining forces and resultant force vectors for machining of reinforced plastics, Cirp Ann-Manuf Techn. 60 (2011) 69-72.

[10] G. Gelfusa, S. Turchetta, Cutting force and tool wear of single diamond-coated bead, Int J Adv Manuf Technol. 72 (2014) 1063-1072.

[11] C. Wang, R. Clausen, Marble cutting with single point cutting tool and diamond segments, Int J Mach Tool Manu. 42 (2002) 1045-1054.

[12] C. Wang, R. Clausen, Computer simulation of stone frame sawing process using diamond blades, Int J Mach Tool Manu. 43 (2003) 559-572.

[13] W. Polini, S. Turchetta, To characterise diamond mill wear, Wear. 255 (2003) 1414-1420.

[14] W. Polini, S. Turchetta, Evaluation of diamond tool wear, Int J Adv Manuf Technol. 26 (2005) 959-964.

[15] W. Polini, S. Turchetta, Monitoring of diamond disk wear in stone cutting by means of force or acceleration sensors, Int J Adv Manuf Technol. 35 (2007) 454-467.

[16] A. Di Ilio, A. Togna, A theoretical wear model for diamond tools in stone cutting, Int J Mach Tool Manu. 43 (2003) 1171-1177.

[17] A. Ersoy, S. Buyuksagic, U. Atici, Wear characteristics of circular diamond saws in the cutting of different hard abrasive rocks, Wear. 258 (2005) 1422-1436.

[18] J. Zhou, J. Zhang, H. Zhou, Wear characteristics of diamond segments on multi-blade combination saw with different diameters in granite sawing, Int J Refract Met Hard Mater. 97 (2021) 105517.

[19] J. Konstanty, Theoretical analysis of stone sawing with diamonds, J Mater Process Tech. 123 (2002) 146154.

[20] J. Konstanty, D. Tyrala, Wear mechanism of iron-base diamond-impregnated tool composites, Wear. 303 (2013) 533-540.

[21] F. Bayram, S. Kulaksiz, Evaluation of rock cutting performance of diamond segmented frame saw in terms of diamond segment wear, Int J Rock Mech Min Sci.139 (2021) 104657.

[22] H. Zhang, J. Zhang, Z. Wang, A new frame saw machine by diamond segmented blade for cutting granite, Diam Relat Mater. 69 (2016) 40-48.

[23] L. Li, J. Wang, J. Li, Research and Structure Design on Systems of Stone Frame Sawing Machine with Optimal Cutting Movement, Key Eng Mat. 250 (2003) 297-302.

[24] C. Wang, C. Rolf, Frame Sawing of Stone - Theory and Technology, Key Eng Mat. 250 (2003) 171-180.

[25] Q. Sun, J. Zhang, Z. Wang, Segment wear characteristics of diamond frame saw when cutting different granite types, Diam Relat Mater. 68 (2016) 143-151.

[26] S. Wang, J. Zhang, P. Dong, Comparison of wear characteristics of diamond segments under different sawing modes in sawing hard stone, Int J Refract Met Hard Mater. 87 (2020) 105149.

[27] A. Ersoy, S. Buyuksagic, U. Atici, Wear characteristics of circular diamond saws in the cutting of different hard abrasive rocks, Wear. 258 (2005) 1422-1436.

[28] H. Huang, G. Huang, X. Xu, An experimental study of machining characteristics and tool wear in the diamond wire sawing of granite, P I Mech Eng B-J Eng. 227 (2013) 943-953.

[29] S. Najmedin Almasi, R. Bagherpour, R. Mikaeil, Analysis of bead wear in diamond wire sawing considering the rock properties and production rate, B Eng Geol Environ. 76 (2017) 1593-1607.

[30] D. Tumac, A. Shaterpour-Mamaghani, Estimating the sawability of large diameter circular saws based on classification of natural stone types according to the geological origin, Int J Rock Mech. Min Sci. 101 (2018) 18-32.

[31] P. Dong, B. Huang, J. Zhang, Investigation and improvement of wear nonuniformity of diamond tools in sawing granite, Int J Refract Met Hard Mater. 83 (2019) 104961.

[32] H. Zhang, J. Zhang, P. Dong, Investigation of the sawing performance of a new type of diamond frame saw machine, Diam Relat Mater. 84 (2018) 11-19.

[33] H. Zhang, J. Zhang, S. Wang, Comparison of wear performance of diamond tools in frame sawing with different trajectories, Int J Refract Met Hard Mater. 78 (2019) 178-185.

[34] S. Webb, W. Jackson, Analysis of Blade Forces and Wear in Diamond Stone Cutting, J Manuf Sci E. 120 (1998) 84-92.

[35] P. Dong, J. Zhang, C. Ouyang, Investigation on sawing performance of diamond frame saw based on reciprocating swing in processing hard stone, J Mater Process Tech. 295 (2021) 117171.

[36] X. Li, Y. Gao, Y. Yin, L. Wang, T. Pu, Experiment and theoretical prediction for surface roughness of PV polycrystalline silicon wafer in electroplated diamond wire sawing, J Manuf Proces. 49 (2020) 82-93. 
[37] M. Li, M. Huang, Y. Chen, P. Gong, X. Yang, Effects of processing parameters on kerf characteristics and surface integrity following abrasive waterjet slotting of Ti6Al4V/CFRP stacks, J Manuf Process. 42 (2019) 82-95.

[38] AS. Saha, KM. Amanat, Rebound hammer test to predict in-situ strength of concrete using recycled concrete aggregates, brick chips and stone chips, Constr Build Mater. 268 (2021) 121088.

[39] D. Brown, J. Glancey, Stability and Fatigue Analysis of Long-Span Continuous Band Saw Blades. ASME ASME 2006 International Mechanical Engineering Congress and Exposition. Chicago, Illinois, USA. (2006) 977-985.https://doi.org/10.1115/IMECE2006-14402 


\section{Supplementary Files}

This is a list of supplementary files associated with this preprint. Click to download.

- GraphicalAbstract.tif 